\title{
Natural Resources Canada's Induced Seismicity Research Project: An Update
}

Honn Kao ${ }^{1}$, Maurice Lamontagne ${ }^{2}$, Denis Lavoie ${ }^{3}$, and John F. Cassidy ${ }^{1}$ 1-Geological Survey of Canada, Sidney, BC 2-Geological Survey of Canada, Ottawa, ON 3-Geological Survey of Canada, Quebec City, QC

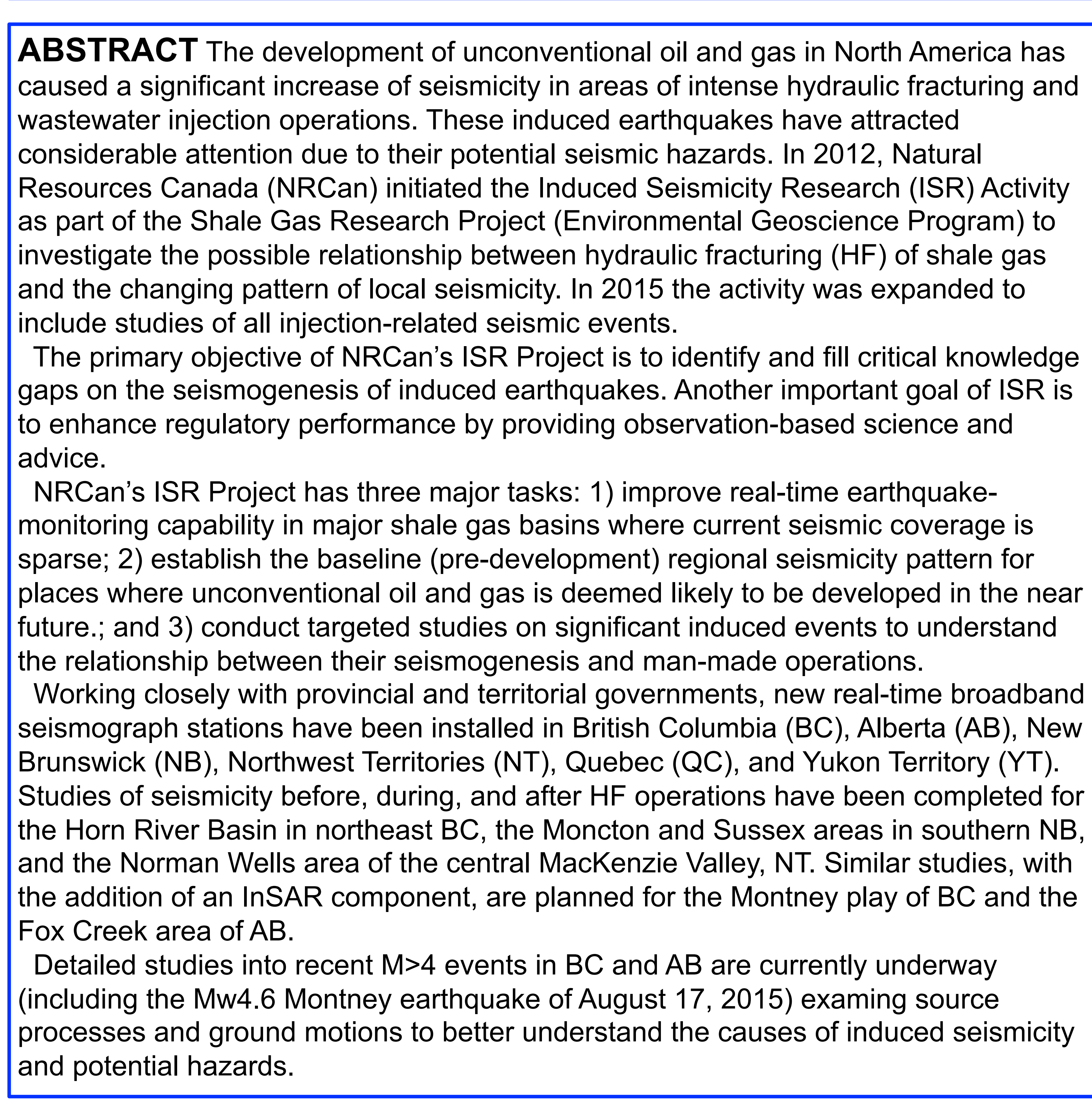
and potential hazards.

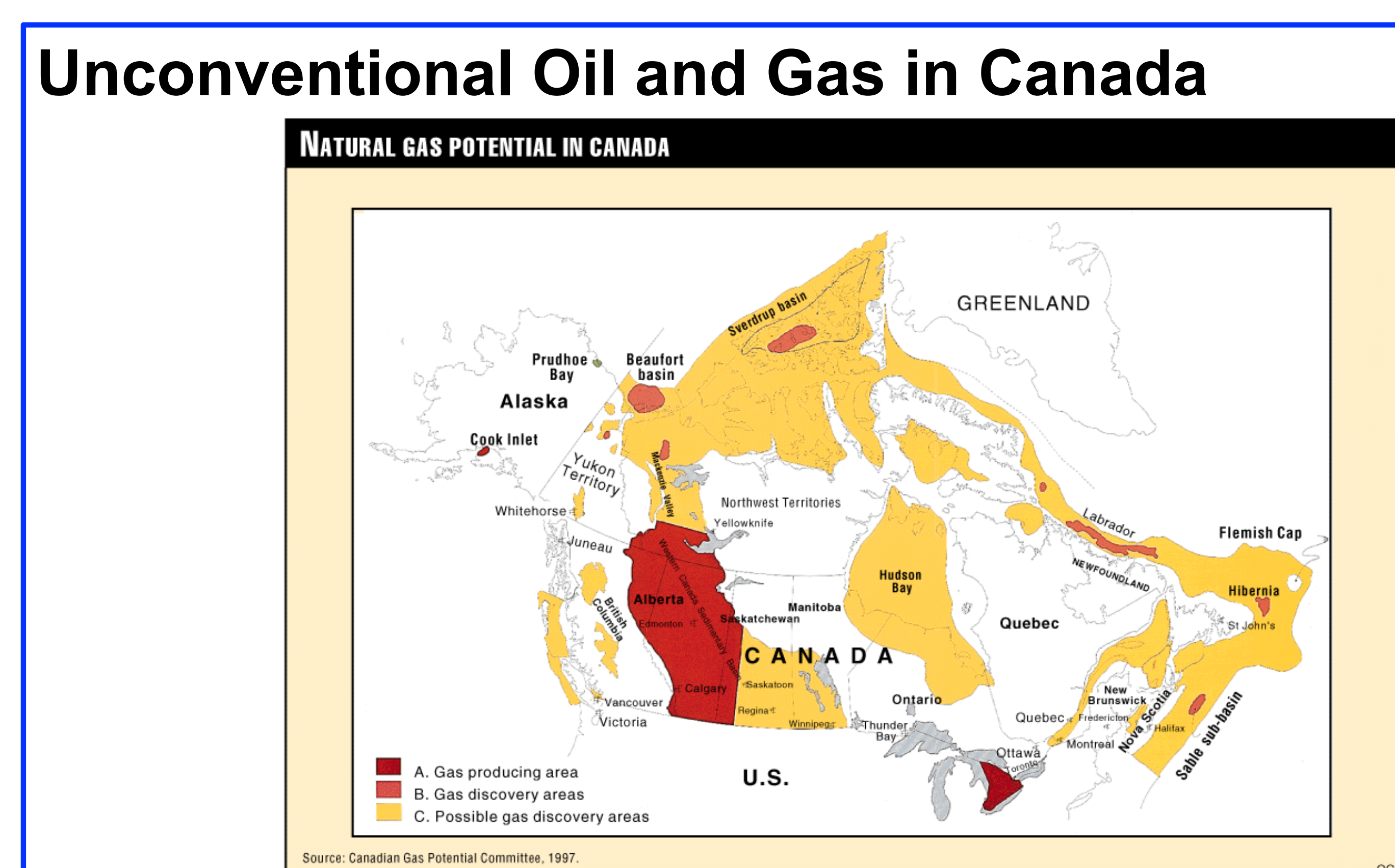

Key Targeted Areas

Basin, including British Columbia, Alberta, Saskatchewan, Yukon, and Northwest Territories.
Maritimes Basin, including New Brunswick and Nova Scotia. Maritimes Basin, including New

ISR for Norman Wells in Central McKenzie Valley, NT

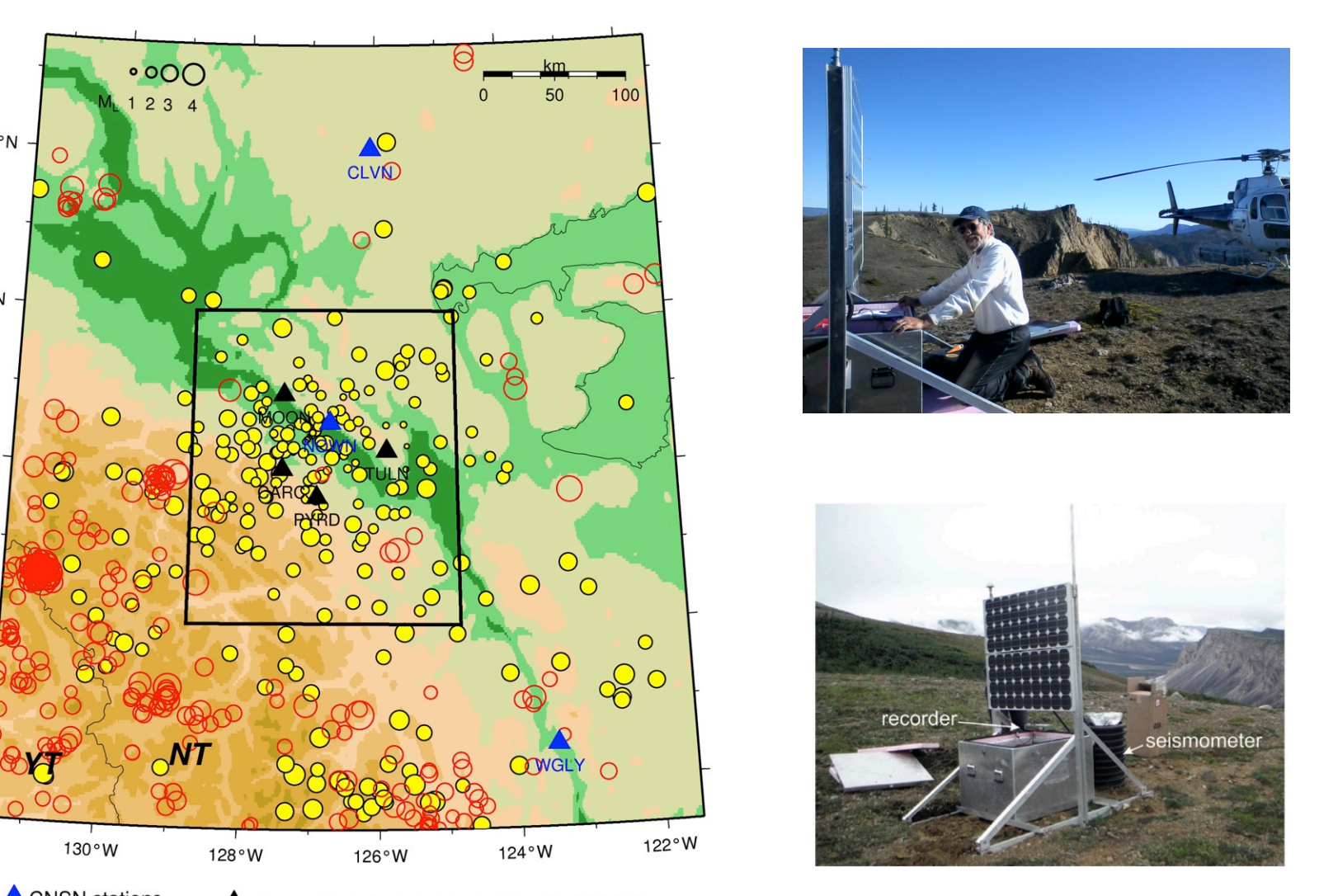

A local array was westablished in 2013 to better monitor the Many small evernts were identified and located (yellow dots)
that were not reported in the national earthquake database.
(Cairns et al., 2014)

\section{ISR for northeast BC}

1. Densification of Regional Seismograph Network
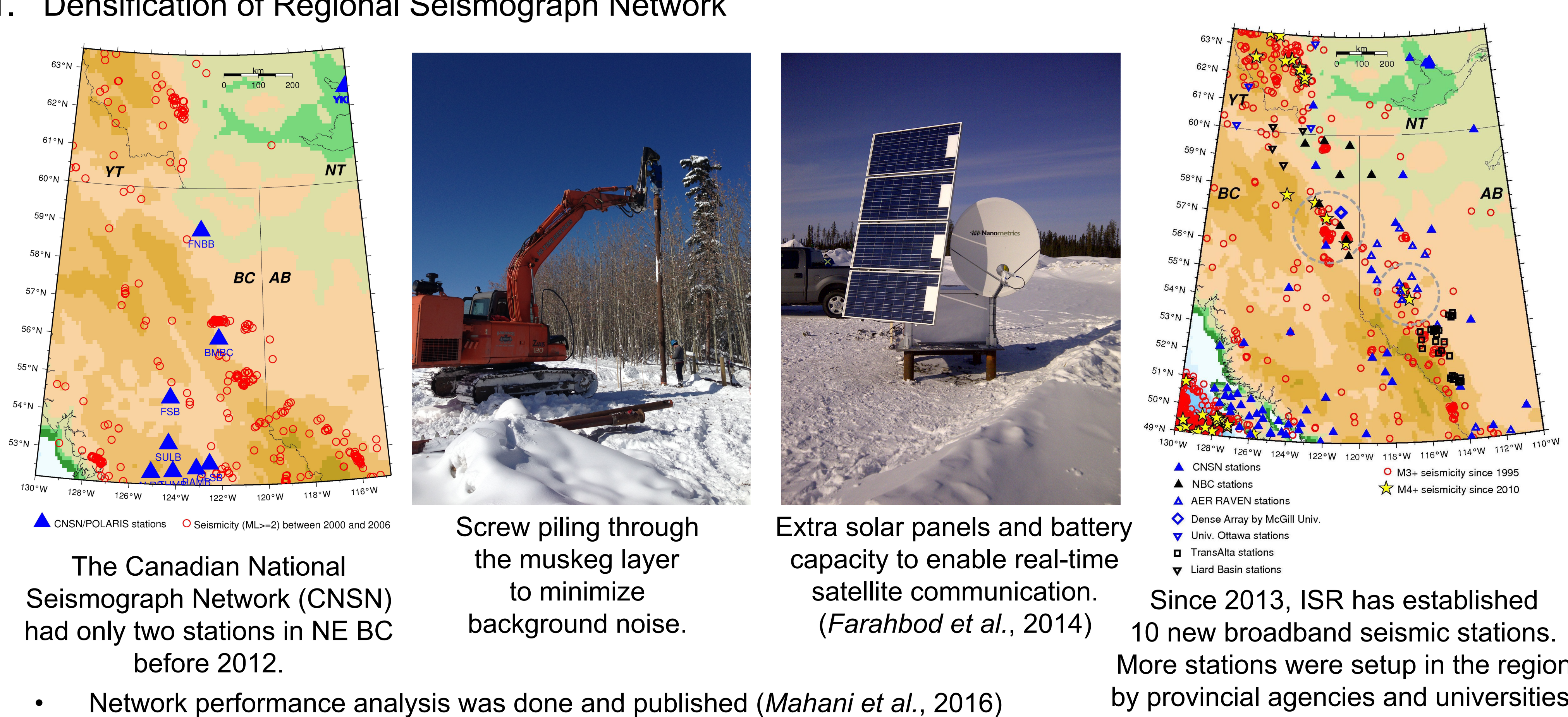

Network performance analysis was done and published (Mahani et al., 2016

by proviniial agencies and universities

Establishing the baseline of background seismicity for the Horn River Basin, BC
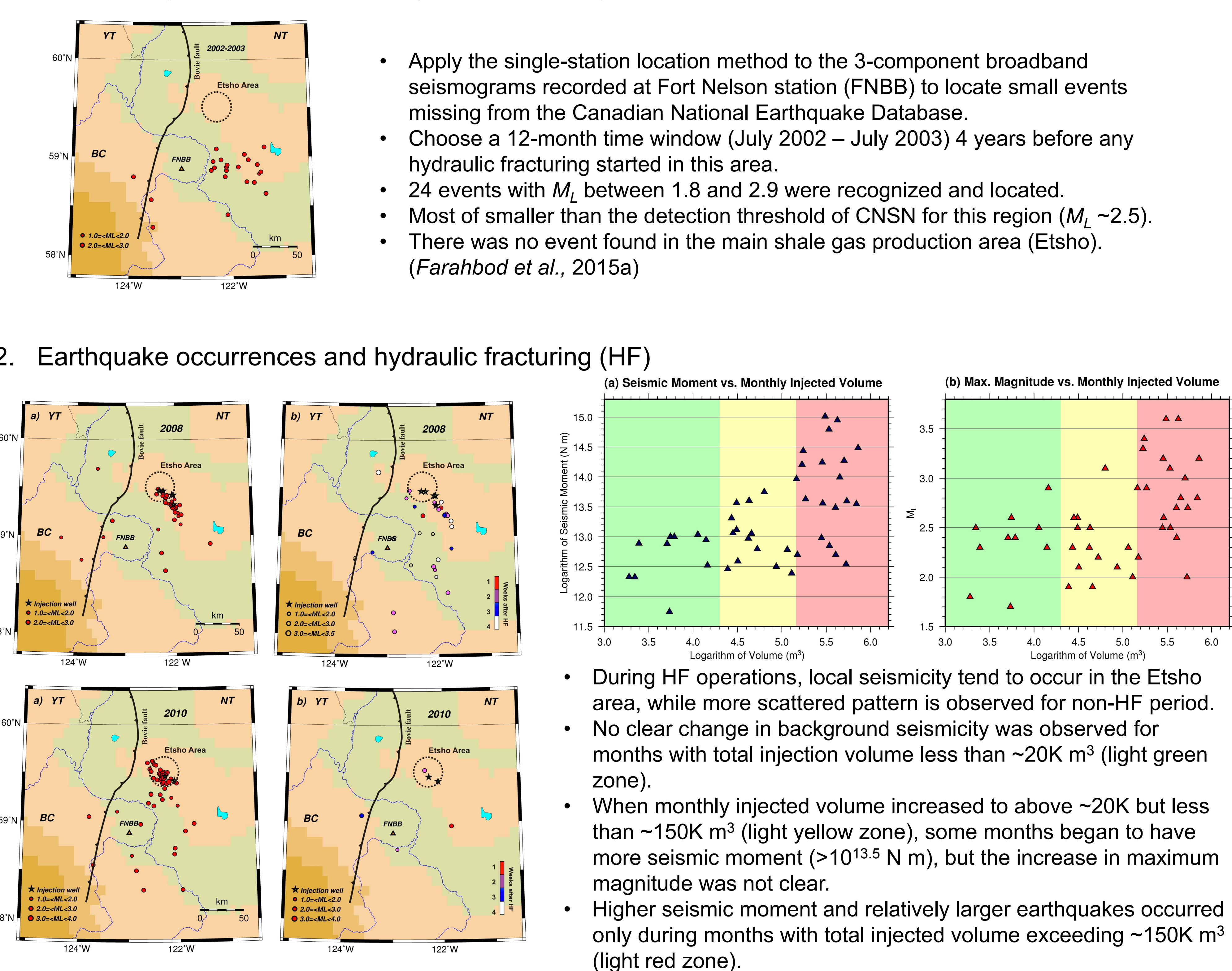

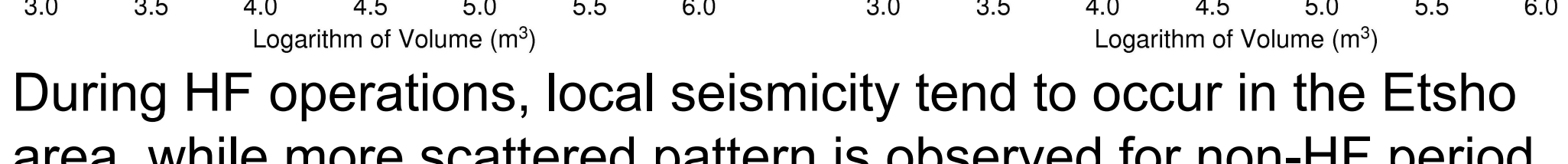
No clear change in background seismicity was observed for
months with total injection volume less than $\sim 20 \mathrm{~K} \mathrm{~m}^{3}$ (light green zone).
When monthly injected volume increased to above $-20 \mathrm{~K}$ but less When monthly injected volume increased to above $\sim 20 \mathrm{~K}$ but less
than $\sim 150 \mathrm{~K} \mathrm{~m}^{3}$ (light yellow zone), some months began to have
more seissmic moment $\left(>10^{13.5} \mathrm{~N} \mathrm{~m}\right.$ ), but the increase in maximum

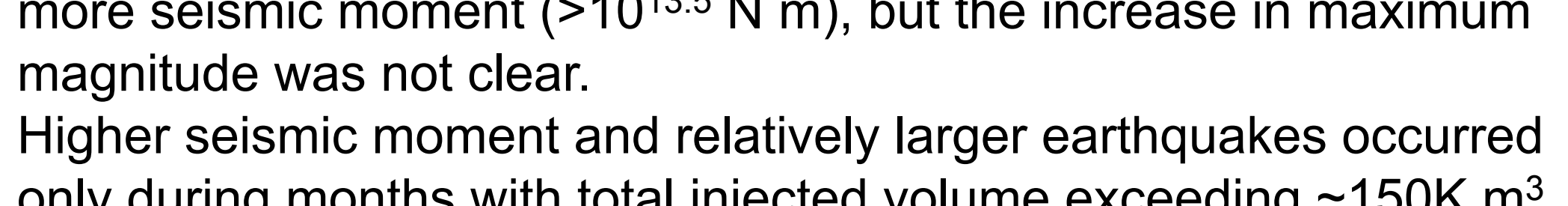
only during months with to
(Fight red zone).
(Farahbod et al., 2015b)

Technical Meetings on Regulatory Performances for Induced Seismicity

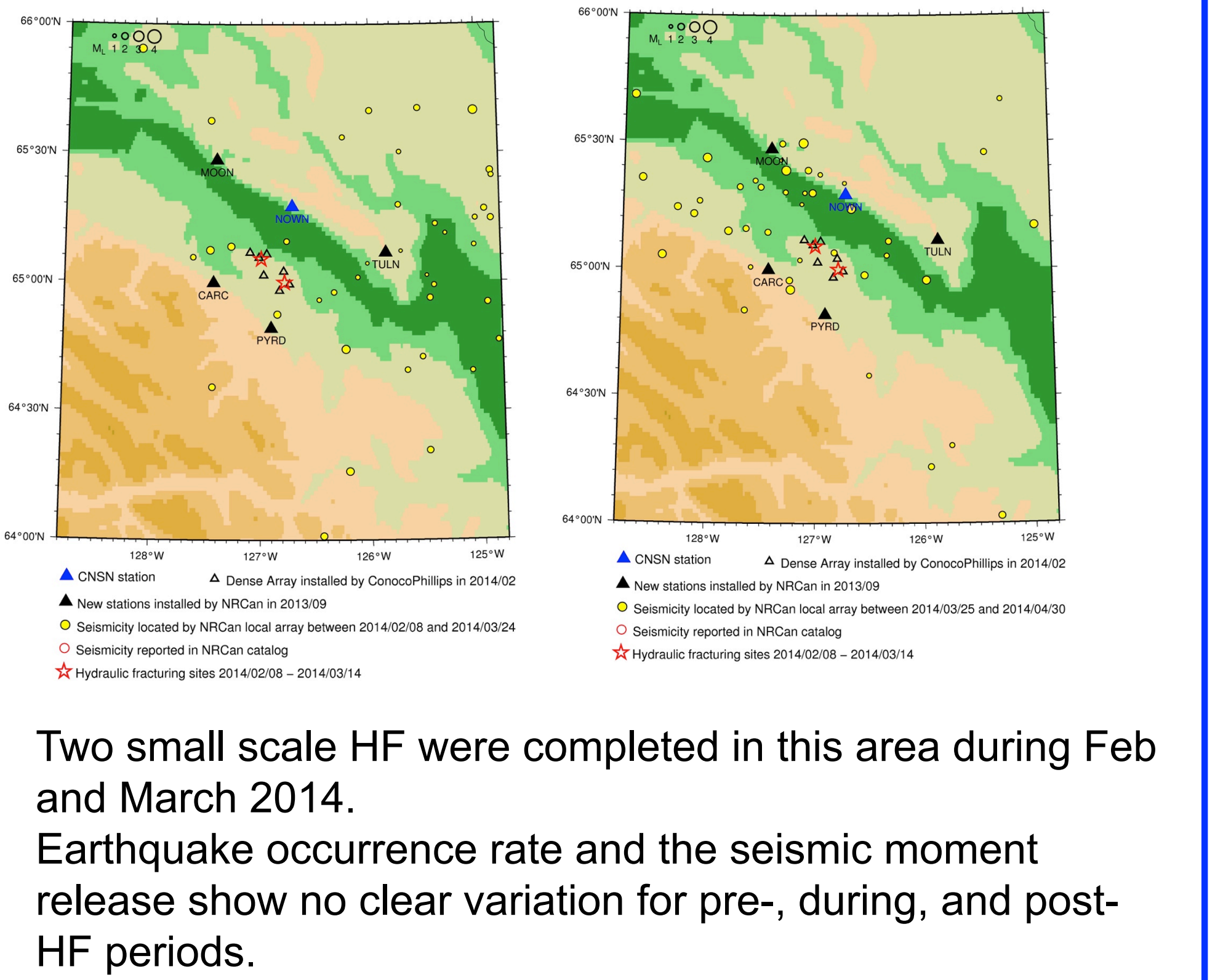

Two small scale HF were completed in this area during Feb Earthauake occurrence rate and the seismic moment
release show no clear variation for pre-, during, and post-

- Oct. 6, 2015, at the Downtown Campus of the Unive "Traffic Light Protocol (TLP) for Induced Seismic
64 participants; 64 participants;
Meeting conclu published S a GSC Open-File Report (Kao et al., 2016).

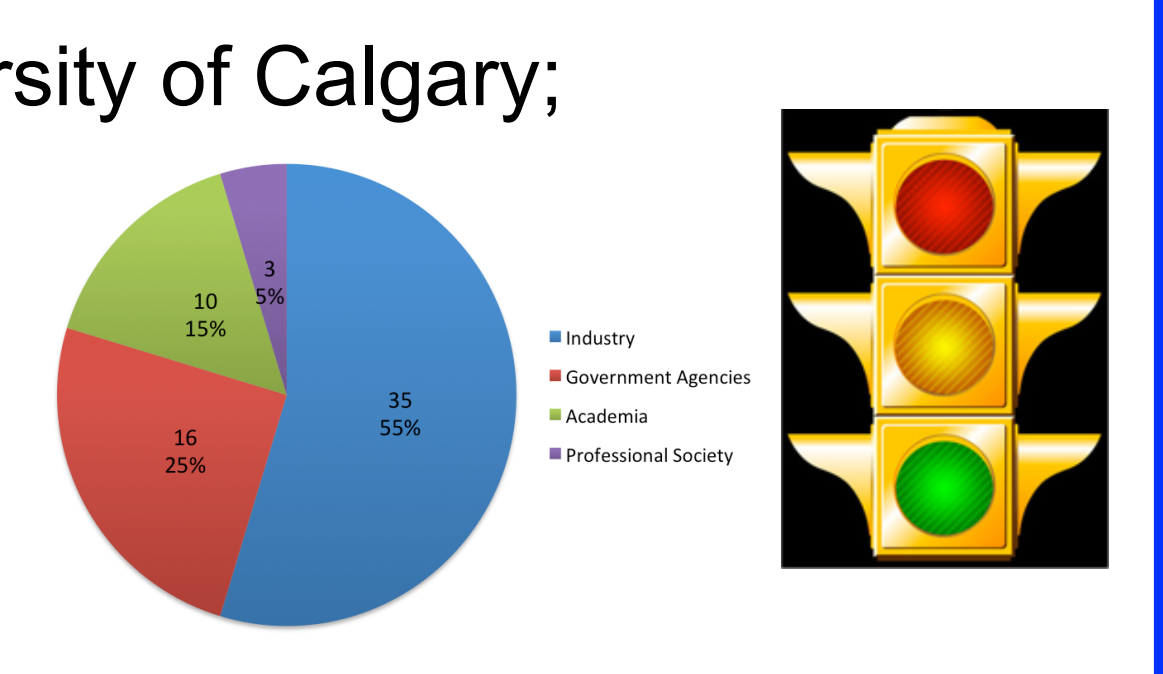

Jan. 29, 2016, at the GSC-Pacific Sidney office: "New Regulation Proposal for Induced Seismicity and Data Sharing Framework";

73 articipants;
Will have a follow-up meeting in Spring 2017.

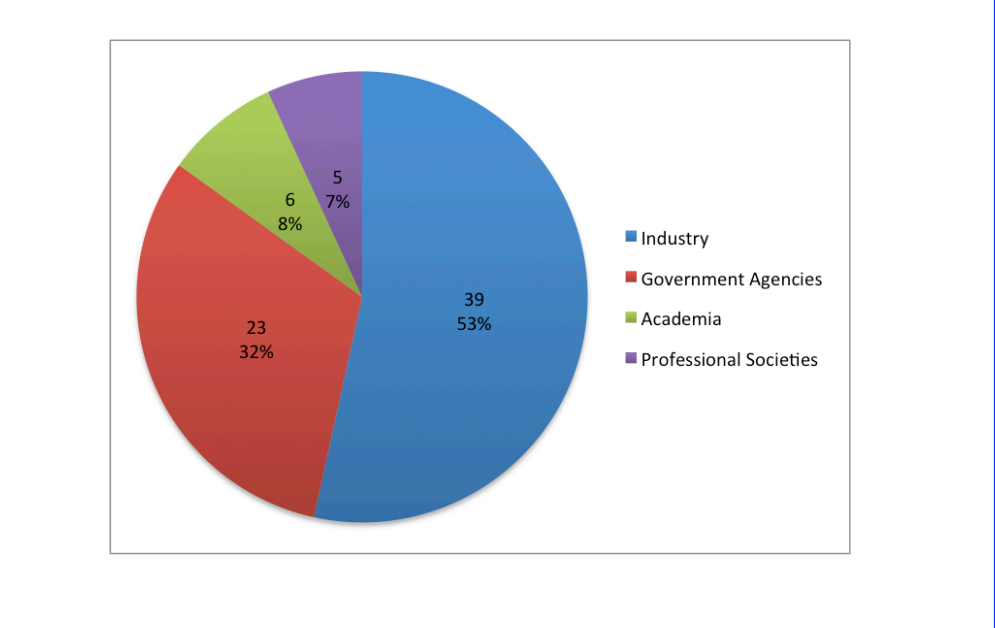

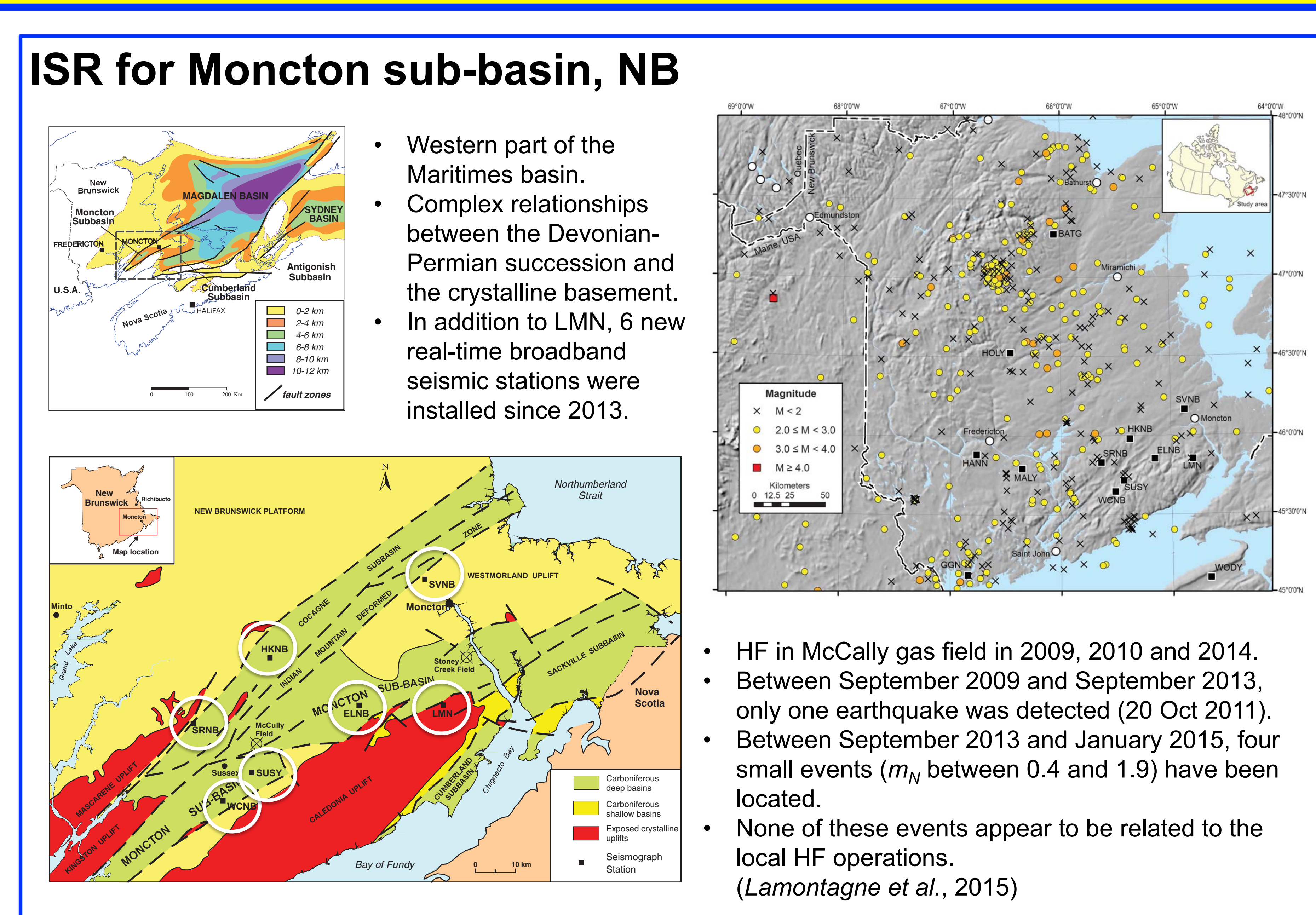

\section{Working Progress}

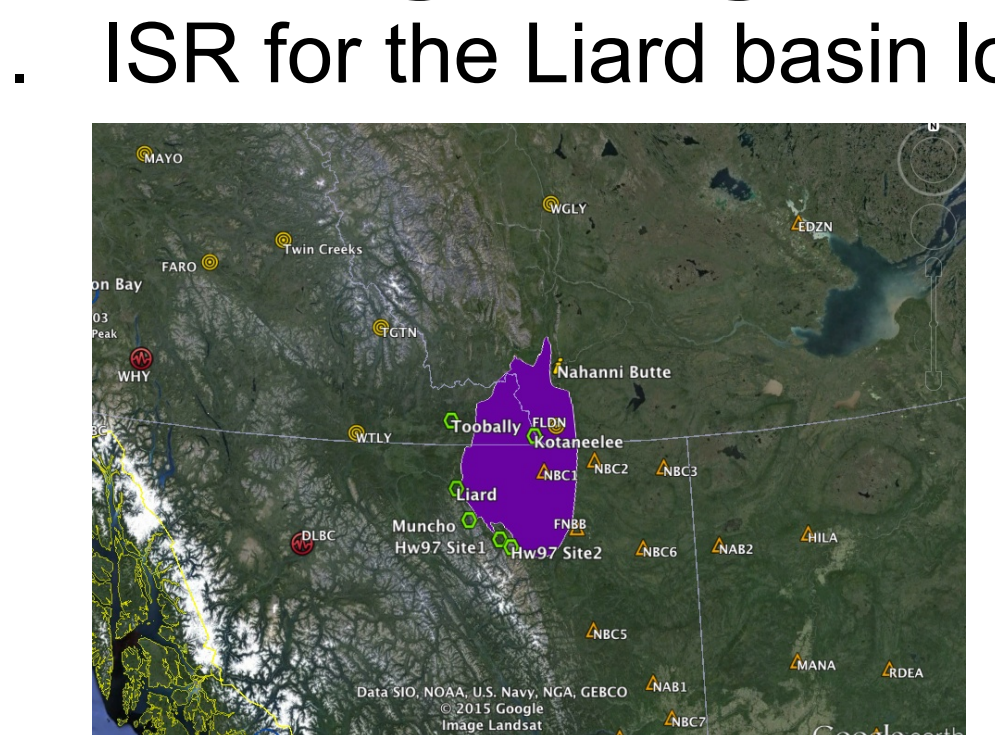

in southeast Yukon Territory and northeast BC Funded by both the Yukon government and NRCan to install 5

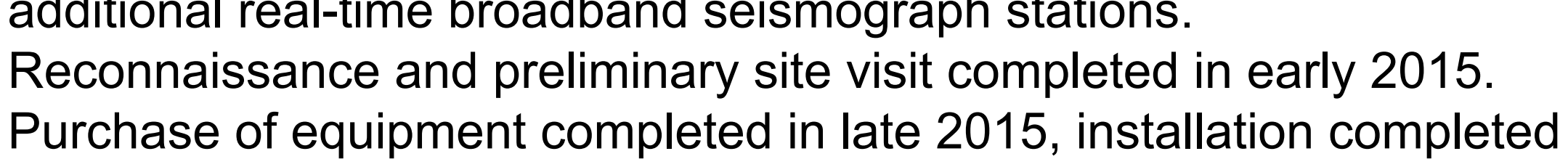
in mid 2016 Project goali: establish a reliable baseline of regional seismicity in
preparation for possible future development of shale gas.

SR for the Anticosti Island, $Q C$
Exploration for unconventional oil and gas is currently underway.
HF operatitins for extracting tight oil and
shale gas are planned in the near future.
Installation of $3-4$ broadband seismic stat Installation of $3-4$ broadb
completed in late 2015.

Detailed studies of recent induced earth $2010-10-05, \mathrm{HRB}, \mathrm{BC}, \mathrm{M}_{2} 3.6$
$2011-05-19, \mathrm{HRB}, \mathrm{BC}, \mathrm{M}_{w} 3.6$ 2013-05-28, northern Montney, $B C, M_{L} 4.2$
2014-08-04, northern Montney, BC, $M_{w} 4.4$
$2015-01-23$ $2015-01-23$, Fox Creek, $A B, M_{w} 4.4$
$2015-06-13$, Fox Creek, $A B, M_{w}^{4.4}$
2015-08-17, northern Montney, $B C, M_{w} 4.6$

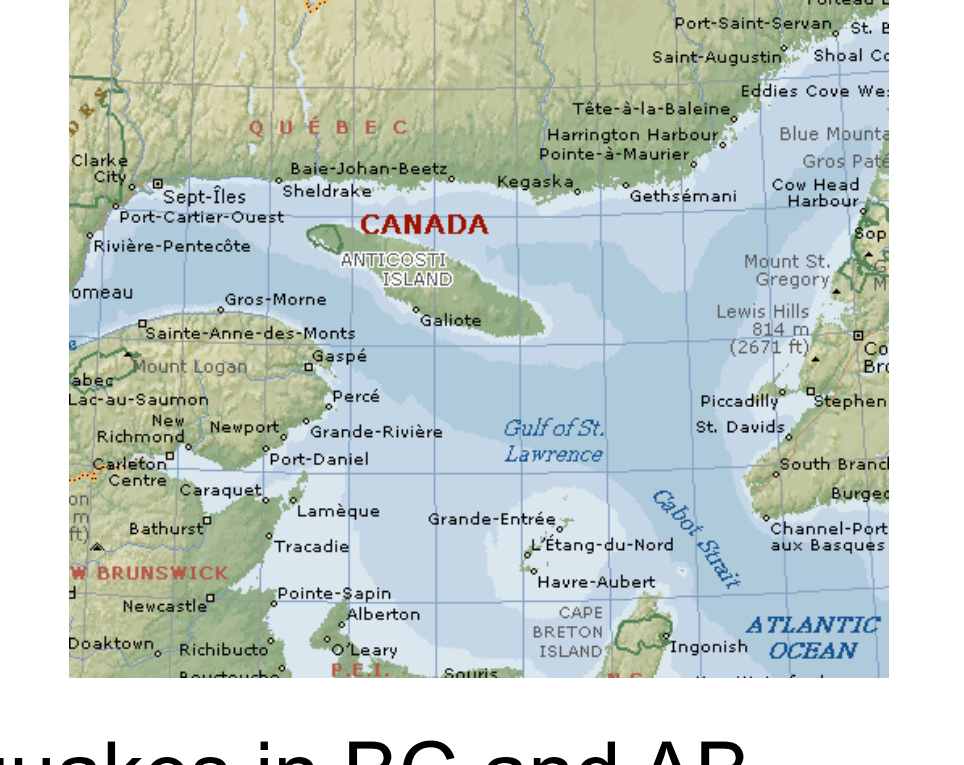
uakes in $B C$ and $A B$ Maximum size of HF-related
induced earthquakes keep ncreasing since 2010 "The largest hydraulic

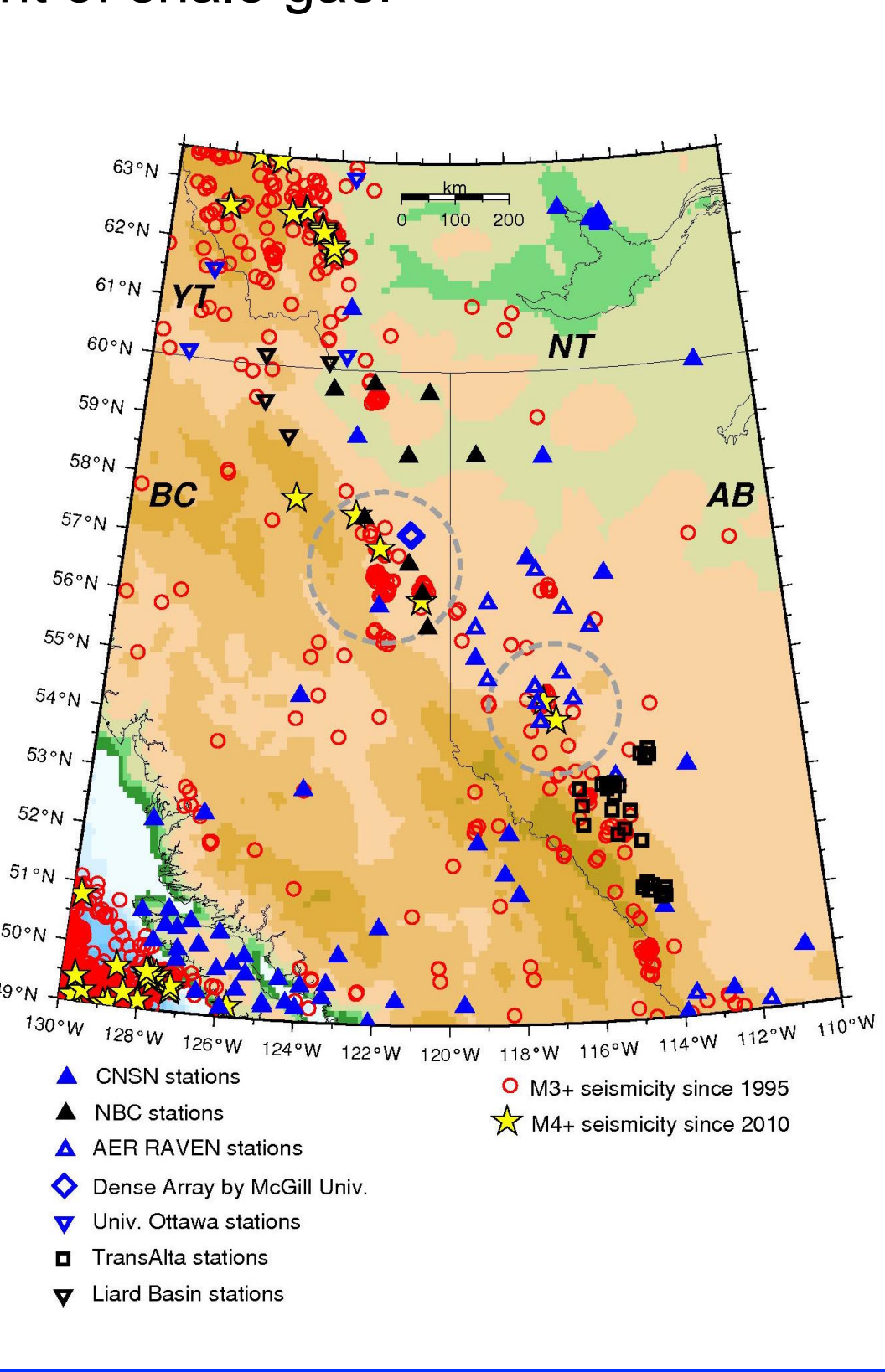

\section{References}

Cairns, S., H. Kao, A.M. Farahbod, and D. Snyder (2014). Preparing to monitor and distinguish natural and induced seismicity near
Norman Wels, Northwest

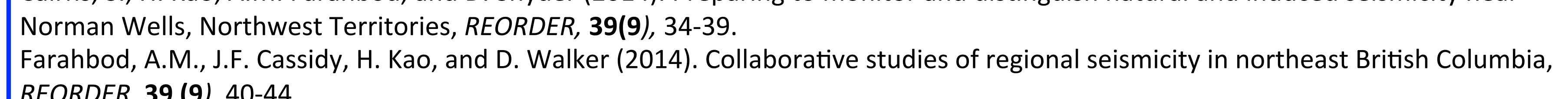
Farahbod, A.F., H. Kao, D.M. Walker, and J.F. Cassidy (2015a). Investigation of regional seismicity before and after hydraulic fracturing
in the Horn River Basin, northeast Brititsh Columbia, Can. J. Earth Sci, 52(2), 112-122, doi:10.1139/(jes-2014-0162.

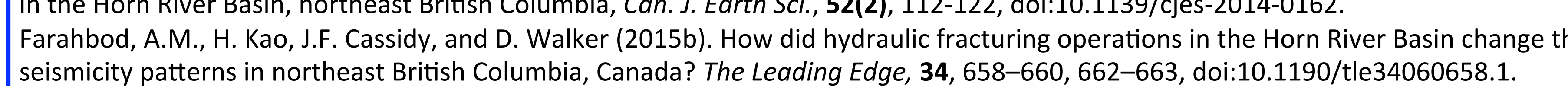

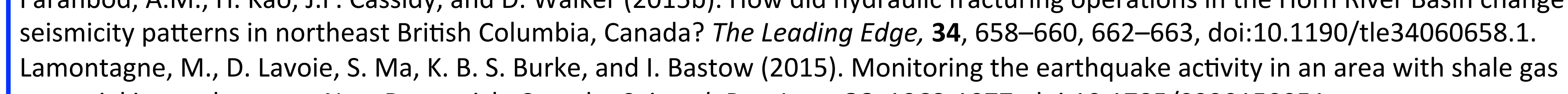

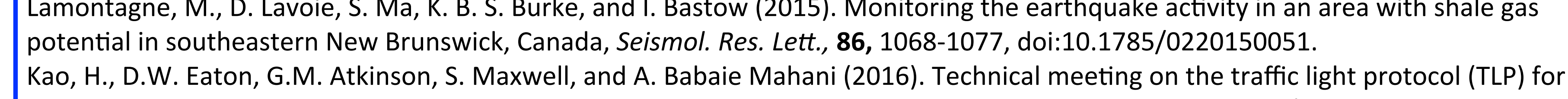

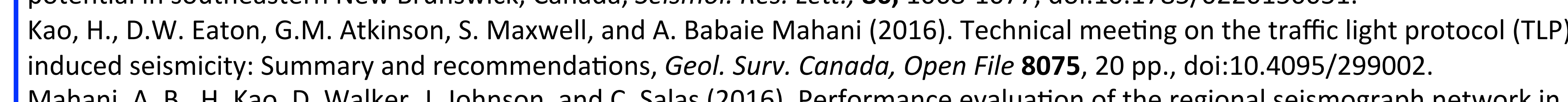

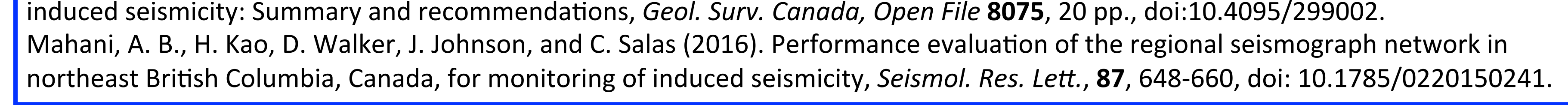

\section{External Collaborators}

BC Oil and Bas Commission, Aberta Energy Regulator,
Northwest Territories Geoscince Office, New Brunswick Department of Energy and Mines,

Ministere des Ressources Naturelles du du Quebece, Yukon Geologicar Survey,
Norther

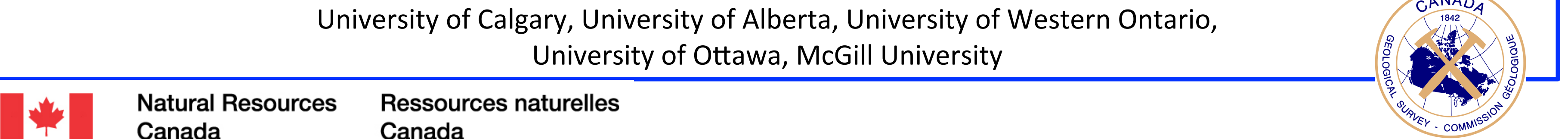

